\title{
Model Study of Decision Support System for Water Management
}

\author{
S. Venkatcharyulu ${ }^{l}$, and Dr.G.K. Viswanadh ${ }^{2}$ \\ ${ }^{1}$ Assistant professor Gokaraju Ranga Raju Institute of Engineering and Technology Hyderabad, India and \\ Research scholar, Department of Civil Engineering, JNTUHCEH, Kukatpally, Hyderabad, India \\ ${ }^{2}$ Professor of Civil Engineering and Director, UGC-HRDC JNTUH, Kukatpally, Hyderabad, India
}

\begin{abstract}
Decision making system (DSS ) is Integrated, interacting tool with information which provide solutions or answers to the policy makers, Dss users, End users to make quick and useful decision. In this paper it is reviewed Dss model based journal papers and presented various model functionality and description of methodology that are used. It is also discussed about literature review of that papers. Most of the water resources journal papers are published on various approaches are based on Software used decision making. Dss in Inida is required for the water management and hydropower management. Several papers published GIS based decision making and papers emphasis on computer based decision making. Quick review of Dss with few number (14) reviewed and presented in this paper.
\end{abstract}

\section{Introduction}

In the earlier Dss has implemented in normal computer based application, user inter face and a available database but today there are Many changes and advancements are taken in the Dss implantation of water management .Dss Model approach by taking the support latest and present technologies. GIS Geographic Information Systems has significant impact on hydrologic displaying and model improvement. This paper investigates connections between data innovation and hydrologic variables of water and DSS. Try to portrays theoretical And partial and brief description about the previous Dss papers (13). Generally various components are used in the decision making. These components are integrated to obtain the efficient water related management. Dss components are generally contains estimated information, data and storage database with software, user interface, system structure, economical and procedural policies etc. Most of the Dss are software based analysis where data require inputting in to the system by the end users and running the existing model.Finally decisions makers can make the decision according to the availed result from the model. . Generally models are developed to run the many variables of any water systems.

\section{Literature review}

Model may be a optimization models, mathematical model, and software programmed with user interfaces etc. Since there are Various sources in the literature shown great development in the many recent years (2002 .,Lam et al 1998; Frederics et al. 1995;Salewicz, Loucks et al.(1) K.A Salewicz, MNakayama et.al (2015). Dss action depends on the behaviour of the particular system process of water problems Components of dss and challenges to solve the problem etc. Dss in water management has carried out using previous journal papers. Because of day by day water scarcity increasing there is need of water management with respect to various requirements has become very essential. Review of Dss with few number (14) reviewed and presented in this paper.

\subsection{Multipurpose Hydropower energy water management.}

Dss water management has one of the focused area where hydropower management with available water in the dams without effecting other human water needs. This also called the avoiding confliction management. The energy graph shown in the Fig.2 India water availability for the various iiragation, industrial, Drinking. Other purposes. Energy generated in India from the multipurpose dams, but due to unavailability of river water, Power generation reduced in the hydropower plants.

\section{3 .Methodology}

DSS is very important for the water management and analysation hence I reviwed few papers (14 No) and partially described the Dss work executed in the papers . From each paper description of work has studied and mentioned it brifly to my extent.

Dss is a specialized area in which it involve the both technology and concept. Hence Papers are chosen old and new papers and describing very briefly about work executed in the paper. Selecting criteria is random and

\footnotetext{
* Corresponding author: vsrini51@gmail.com
} 
review has limitation with description on the whole of the paper in brief as limitation

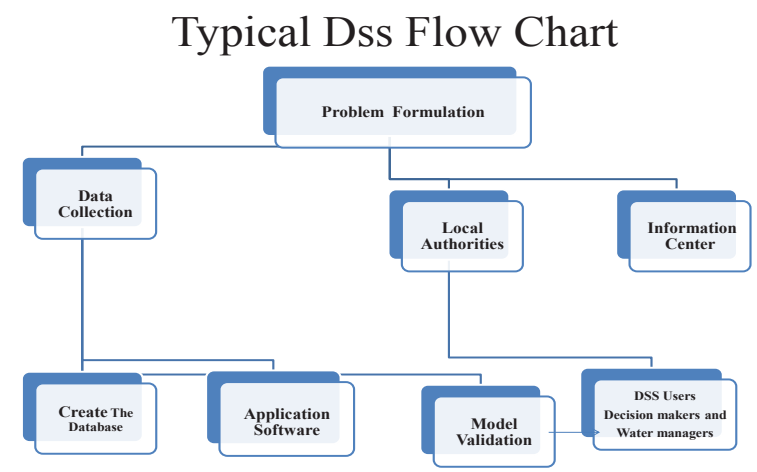

Fig.1 Décision Making Procès For The Typical Problem Formulation

\section{4 .K.A Salewicz,MNakayama et.al (2004)}

Notable capacity for the use of the decision support system are considered and also Discussed about the Dss models in earlier for the water Management . important discussion from this prototype software, First, there may be shared basins of rivers, all fair and clear Dss systems by considering systematic approach of shared basins . Secondly, there are many challenges in complete application of the DSS methods, which many of them resolved with study for the further development. Max number of scholars been running on development of different strategies and particular tools to handled. In this paper contains conversation of the fundamental improvement of decision dynamically supportive networks (DSS). Expanding upon this establishment, the issues related to making of of DSS are given both an investigation of data require exploration while decisions imposing usage of water asset frameworks.

In this paper DSS created for water asset frameworks are given and issues related Improvement of DSS on web is examined. A model Web technology based choice help framework produced for dissecting outcomes of different strategy choices in a huge global rivers (Ganges River) is introduced. It is stated two principle from this model application. 1) Initially, there is incredible potential for utilizing the DSS to attempt precise the executives of shared stream basins prompting powerful compromise. 2) Next one is Number of difficulties in complete usage of the DSS, That can settled By innovative work. This examine task is to creation of a Web technology based DSS prototype, trusted beyond reviews in growing conventional DSS. This Web technology based DSS capable of addressing troubles in usage of water sources in shared basin river water. It is advantages of Internet technology which is scope of being used in present research and developments in addition Web technology based DSS packages.

Prototype Web technology based totally DSS evolved for analysis audience. The Web-based DSS in experience in modelling who require assessing the quality will effects various policy alternatives of their river basin.
Web technology based Dss are visualized and effective in water management. This paper Used client and server technology and focused on three major group of activities selected a river and formulated decision problems and implemented the Dss in visual WebPages and dialog screens. Final result achieved by approach methodology of designing the web pages Used a simple case study of implanted application and finally utilized the reusable software. Future scope of the research that can implemented high configure reliable software and with high internet speed. In this paper web technology and software technology combined for Dss water management .

\section{Jaroslav Mysiaka, Carlo Giupponi b,c, et.al, (2003)}

Towards Dss for water management, the accomplishment of DSS advancement is questionable and many automated choice help solving and presenting issues. This paper depicts advancement philosophy development of mDSS, (MULINO Dss) it is a choice for dynamically supportive network for water management that has been created under procedures. Many of models have been created and the last form is normal toward the finish in three year venture. Framework's improvement in obtained in a few contextual analyses chose in five European nations. In spite of the fact that the primary point of the MULINO venture and the Dss is to help with progressively critical choices for water executives and also sustain the river water basins .It also handling the frame work of water management. Mulino DSS soft ware is used in this paper for water management and which is known as mDss development. The DPSIR system is used ' $p$ ' is pressure ' $d$ ' is driving related force.. ' $S$ ' indicates state ' $I$ ' refer to impact and ' $R$ ' represents response. The base developed for $\mathrm{mDss}$. are first and second mDss soft ware is developed and further frame work has continued development. Multi criteria Approach is used for the development of MULINO-DSS

The MULINO venture is occupied with creating a decision software which aid in water management by executives and which promotes ideas for the water frame work design .some resolution confliction identified by usages of storage water, either two gatherings some group of people require water for irrigation maintenance. This has done by strategic way by Dss management. Finally requirements of groups for their water needs which has guided by mDSS's water applications . Finally this frame work used to evaluate the decision water management solution. 
Three types of water requirements first one is drinking purpose. Second, Gathering requests for water for

Table. 1 Future Energy requirement of water management in India

\begin{tabular}{|l|c|c|c|c|c|}
\hline Sector & Domestic & Irrigation & Industry & Energy & Other \\
\hline Share of sector in 2000 & 6.6 & 85.3 & 1.3 & 0.3 & 6.5 \\
\hline Share of sector in 2025 & 6.7 & 83.3 & 2.1 & 1.4 & 6.6 \\
\hline Share of sector in 2050 & 7 & 74.1 & 4.4 & 9 & 5.5 \\
\hline
\end{tabular}

Future Energy Requirment of water Management in India

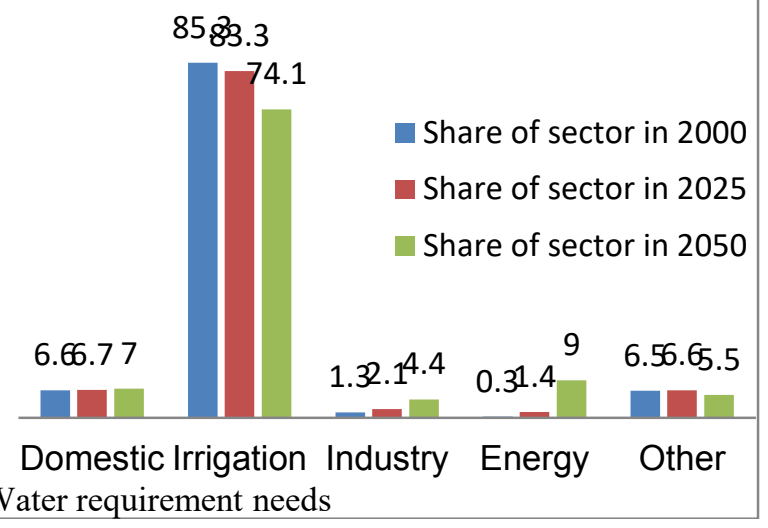

Fig. 2 Water requirement needs and energy requirement Source (cwc) central water commission India

\section{Future Energy and year wise needs required for the water management in India.}

All over the world the quantity of fresh water available nearly 6000 cum (source C.W.C). Because of rapid developments and population growth. In india, presently the available fresh water per capita 1123 cubic meter (sources :cwc). Before this freh water available was 3000cubic meter. Mostly water from the Brahmaputra river in India the usage water will be only 4 percentage. Because of mountains and topography difficult to extract the from the brahaputra river. Hence proper management of Dss water management is require in India.

\section{Veerakcuddy Rajasekaram and K. D. W. Nandalal 2 , et. al 2005}

Dss for the reservoir management for the confliction resolutions. Another methodology is utilized in building up the correspondence framework, in which the utilization of man-made machine language encourages correspondence between users and the framework. Instruments generally are normal to investigate a multi criteria with single supply frame work are given in the model-base administration frame work. RWM-CRSS is intended to deal with strife between two gatherings those had water necessities for the drinking purpose and hydro electric power . In Theoretical situation of water system as opposed to drinking water supply is illustrated. drinking while different requests hydropower. Third, Gathering is demand for the drinking and flood security. Common situation relating both types are portrayed accompanying with Descsion management with multi tasking. This all are done by single supply framework. For such correspondence framework, a database is generated for flood control, hydro electric power, and drinking water supply.

RWM-(reservoir water management ) is compromise needs between the clashing groups is solved

Many water problems . futher it is suggested RWM and CRSS is upgraded by the advancing methods using AI, specifically Artificial Intelligent Machine Language.

In this paper suggested applying Artificial Intelligent Machine Language for correspondence to repository of water executives, is now, cutting edge with innovation are left for future development.

\section{Carlo Giupponi and Yaella Depietri et.al (2002-2006) 2007}

Guidelines Nostrum-Dss Decision support system in the Mediterranean Area .This report provides the Guidelines for the improvement and alertness of Decision Support System (DSS) gear in response and needs of decision makers inside the subject of Integrated Water Resources Management. These Guidelines developed for Nostrum DSS Action ("Network on governance, Science and Technology for sustainable water Resources management within the Mediterranean). This document is planned as an intelligent gadget organized into three areas condensing and encouraging the discussion of the Nostrum-DSS Project's results and other related items.

The primary point in the document is to improve and utilization DSS in the Mediterranean Area, types of commitments are originated from different peoples, primarily from the Harmoni-Ca Concerted Action around to give present day apparatuses to the water control decisions. Carlo Geoponic and Yaella Depietri etal (2004). has provided the diverse reservoir.

( Reservoir problems contain inherent uncertainty) Another critical feature of reservoir inflow and different hydrologic variables deal reservoir operation. Regarding above cited making decision is one of the maximum vital Parts of most excellent reservoir operations. Definitions of DSS inside the field of water resources have provided in distinctive texts and papers or even defined in distinctive approaches relying on the author's factor of view (Barsaand Grusseb, 2008).

The DSS has four primary traits, (Mittra, 1986) 1) It facilitates choice-makers at the upper ranges.2) It is 
bendy and responds fast to managers' questions. 3) It affords "what if" scenarios4) It takes into account the special requirement of decision makers. A fashionable definition of DSS was provided as: Computer-based totally tools having interactive, and modeling traits to deal with precise troubles and assistant individuals in their take a look at troubles and look for solution in their management problems (Loucks and Docosta, (1991).

IWRM has now emerged as an lead to itself, in a few instances water control undermining structures. In nowadays IWRM is answers to current water troubles. In this paper discussion

About water problems and also uses of trans boundary water management governance in suitable way of water management especially related ground water in India . IWRM that are being effectively used to remedy for major water troubles. principal message is that we have to simply get problem solving for global water management challenges

These thoughts are an incredible to express for thinking about improvements in water policy and control, also had been formalized as what has now turn out to be, in capitals, management of water by (I.W.R.M). It has come with an idea UNCED, 1992 under Agenda 21 and included some thoughts from the Dublin 1992 convention 1992 ICWE, ,

IWRM is now often interpreted as consisting of precise techniques. All it is establishing overall water related policy, legal guidelines and it is used as basin as scale of water management deciding the water authorizations, use water costing for fixed money and related some allocation, and encompass included in choice (2006van Koppen, \& Shah).

This paper has two steps, first (1) IWRM has become an lead to itself as opposed to a way to clear up precise demanding situations, thereby diverting assets from realistic troubles and once in a while undermining alternative, functioning structures; 2) Aim is to implementation of IWRM, instead of the answer the water issues and reform again new method; (3) IWRM is used as a device cover more agendas, (4) IWRM focus on water problems and it is alternative solution for the pragmatic water troubles. The second purpose has options to IWRM laboured that might retain to work in destiny. Last message is that IWRM is solution for various problems of water project.

\section{Mazlan Hashim1, Samsudin Ahmad1 and Faidrullah etal, (2007);}

Dss included with Integrated GIS for Water Pipeline leakages . This paper summarized (DSS) dynamic net working models for Non Revenue Water (N.R.W) executed at Water Supply board (TWSD) Temerloh. Related work has executed among the net work and used the RS and GIS along hydraulic models and to anticipate zone of pipeline spillage (leakages) . they cantered on database making of pipeline arrange (utilizing Window software and ESRI with Arc Info 9.x ) used for the frame work. The advancement of Dss for N.R.W dependent on remote sensing, its states the latest water spillage in the housing pipeline line network

Just one test-site ((Felda Bukit Damar Pipeline Network) might be completely approved because of accessibility of records for this investigate. From N.R.W peril map generate, a total of 30 components of exorbitant possibility and incidental threat for water spillage have been distinguished and shown inside the subject. For the entirety of the high possibility factors, $85 \%(26 / 30)$ have at any rate 5 going before record of water spillage in last 5 years, and all the 30 low threat factors, have not been any archive of such rate. Author included a meeting with close by (near by) populace to confirm the entirety of the visited.

Paper features the improvement of a DSS dependent on GIS and RS (Remote sensing ) to calculate water leakage and their possibility. The device appraisal plot that designs water spillage frequency fundamentally dependent on: (a) variable for water pipe gadget factors, such as age of pipe , measurement from ground height, and material of channel ; (b) some other variables are - water request, convey, needs of convey etc (c) Site variables - such as pressure in pipeline due to leakages are recorded by satellite sensors. The client can connect with the framework to make probabilities of pipelines spillages that hyperlink the buyer outfitted establishment and all the above-alluded to three gathering parameters. The realities transformed into built the use of the GIS based absolutely at the location of hubs with the guide of supply area, water call network. The framework transformed into an investigate region in Temerloh, Malaysia Pahang. Main Objective is to make regularity map for location of water leakages.

\section{F.,A. Palma1, González2 et. al, 2015}

Sonora River Basin(SRB) water Managed with Aquifer Recharge Mexico; Arid areas regularly have shortage of water mainly for drinking water supply and agriculture which is addressed in this paper with DSS modal aquifer recharge (MAR) model . Capabilities of Dss are modified by application to watershed of Northern Mexico and there is a many types of agricultural near of small cities along the river. The DSS consists of the water (hydro) modelling system, circulate glide in rivers, the ground-water-drift version such as MAR, and the characterization of the water satisfactory from numerous sources. A hydrological model developed to meet all demands and satisfying all the sources of water quality to meet their demand. From the source water is treated and conveyed for water supply system, irrigation and waste generated after treatment is send to 
lagoons, that recharges the aquifer . MAR is help in meeting the demand of water supply and irrigation needs .

Hydrologic modelling of the SRB DSS scheme advised that it's think about a increases population ,7\% in the basin there by relevant quantity of aquifer water shortage and analyzed period of drought For 25 years Plan developed structures related to hydraulic works and WWTP(waste water Treatement).It is Observed that water shortage in the basin increasing day by day, finally to exchange the compensated by adopting the choice of MAR and utilized in greater appealing in Mexico. It advised the study of coast of Hermosillo to recharge the aquifer water and observing to evaluate the spatial changes in water satisfactory levels.Objectives is to increase storage of water and reduce the demand water by utilizing reusing Treated waste water. Methodology is hydrological (water) model, ground (aquifer) water model are adopted for frame work and MAR is used for the reuse and water quality check.

\section{Jin-Yong Choi, Bernard A. Engel,.} et.al (2005) ; Dss Web-Based System in Regional Water Resources Management .This paper investigates connections between data innovation and hydrologic/water quality investigation DSS. It likewise portrays a theoretical online SDSS structure in terms of framework segments. Further Rossen Iliev et al taken Dss implementation through the WEB technologies. GIS (7)with models related hydraulic data including river basin inclination, viewpoint, stream lines, soil types and various other Information in network and include vector designs. Network design information are generally simple to control contrasted with vector-based information since matrices store "certain topology", while vector information requires "express topology". Frame work in this paper are components related to web as main component. SDSS online contain the HTML language, interface with both user and client, calculation models and finally a database related to geography. It also includes the common interface and server activity.

The languages and soft ware used was Electronic SDSS (7) UIs incorporate screens visual asking inputs control structure with interface utilities guide the choices for input data and utilizing HTML labels, used Java library and other Internet conventions. Decision happening when customer is submitted information and convention and occupations which are executed with Internet user interface .Fundamentally, any SDSS(7) for water quality investigation for river basin the executives founded as a best model to watershed. In this project on line delineation has of the watershed has performed. Finally this paper has reviewed the water quality and technology used to analyze the dss water management. Software technology has used to delineate water shed study area and spatial analysis has carried out by linking the GIS and web base Dss capabilities.

\subsection{Dss of water management}

Dss of water management for the future Demand in India. Has shown in the graph Fig. 3 and Table. 1

Table 2. Future expected demand of water in India

\begin{tabular}{|c|c|}
\hline Year & Water demand(bcm) \\
\hline 2000 & 634 \\
\hline 2025 & 1093 \\
\hline 2050 & 1447 \\
\hline
\end{tabular}

Unit is billion cubic metre (bcm)

\section{Future water Demand Graph}

year water Demand

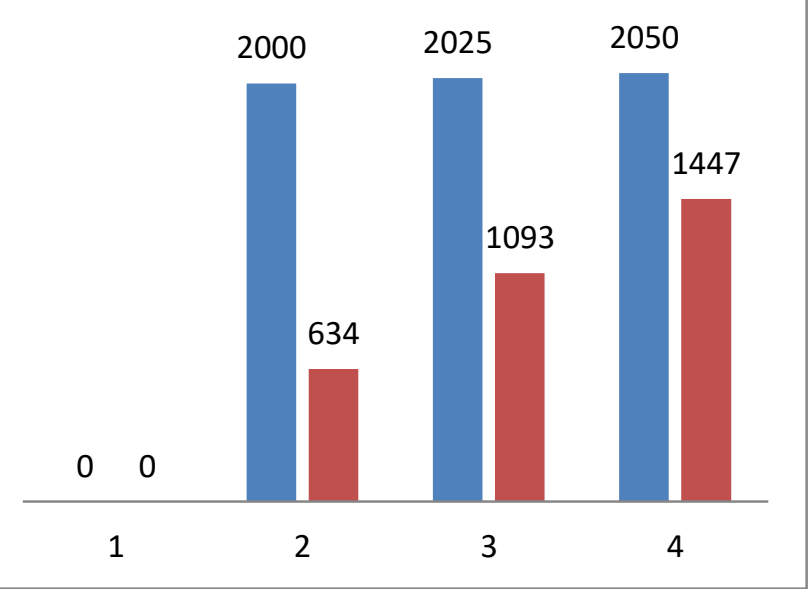

Fig 3. Future water Demand Graph (Source CWC)

\section{Verónica Ruiz-Ortiz, et.al (2019)}

Management of water using Dss and its contribution to climates related high evaporation in the Mediterranean region. The utility of integrative Descision supportive networks (DSS) (for dynamic and complex frameworks ) with various goals permits leaders to recognize qualities and improve water the management in a basin. In this paper has discussed more about the hydro model and water management tools are combined with aqua tools and achieved the better management of the study area( Spain). Increasing of population and irrigation demand decreasing the flow of water (Alcamo etal 2007). Irrigation demand is more in river basin which is to the $70 \%$ nearby. In this paper stated that agriculture demand is more to focus in case of water management straighter . surface water and ground water are two important parameters to the analyzing the dss management. AQUATOOL and SIMGES are used in Dss water management. the quantification of the output contribution by Dss is analyzed in this paper.. Study area of the paper has taken S.W. Spain. Problem related to quality of ground water state is not up to the mark and it is contaminated with the nitrates. WEI (water exploration index ) has considered for the water budget . Present and future demands of water has collected 
involving the parameters such as reservoir storage related gauge, surface water level, irrigation water, ecological flows. These are generated from the automatic hydrological system. Evaporation values are calculated using the penman equations Penman montith equation. evaporation values are calculated and finally compare with previous available values. If near to the $2 \%$ values are taken for the adjustments. Basically aquatool SIMGES module is used with optimization method . in this paper after evaporation losses in the reservoirs quantity of water has estimated. Initially quantity of water is calculated (before evaporation of water) the storage management in monthly scale. Validation in this paper has carried out taking the present data and calibrated with previous data by considering the strategies and used the Dss based tools for water problems in the Spanish river basin.

\section{Baria Satyagraha, Lily Montarcih Limantara et.al (2018);}

(Model of water monetary worth advancement in view of the land use change. There was increase in the surface flow in the rainy season in the study area of the this paper which cause the land topology changes this is due to residential and industrial occupancy. Apart from this, the decreasing storage of flood volume that affecting the crop area in water shed (Rawa Pening) surrounded. Excess of water in the upstream and downstream is effecting changes in the land pattern It is requirement minimize the water grant and economical values for the region. Hence in this Paper focused on the analyzing the land changes due to water availability, water balance and build the optimization model to obtain the economical values due topographic change. Linear programming has used for the optimization model approach. Finally result in the paper was analyzed the benefits with hydroelectric power (timo and jelok) and analyzed the quality of water used for the irrigation and draining purpose in study area.

Carlo Giupponi1 and Alessandra Sgobbi 2 et.al ,Water (2013); (10) DSS of water management in Africa a development country. Dss tool has developed in south Africa by conducted survey of literature on the people agroup of field of experts prepared some questioner and ask them to answer it to start Dss based water management. Most of the survey reveals bout the least used by the Dss end users and the experts says that limited impact on the end users. Responses form the questioneir says that focus on the development of the Dss tool rather then developing the frame work of water management.

\section{N. Arumugam1 and S. Mohan2,et.al .(1997);}

Integration water management for the tank irrigation by operating the system. An integrated choice decision supportive network activity of a small reservoir irrigation in the India is portrayed. Decision support net work incorporates information branch system ,a model contain another branch system and provide the knowledge using the system inter face. The Dss developed by taking the five years data System variables inflow of water and evaporation was used in the operation of tank irrigation. The Veeranam tank water system framework situated in Tamilnadu state, south India, is considered for the current investigation present framework is the biggest tank water system framework in India. In this paper Dss integrated has approached with algorithms techniques has considered with five components data, model subsystems predicting modules , knowledge information and finally user inert face.

\section{David W. Julian1; John T. Hickey2 et.al; (2016).}

Dss for resources of water and environment in the Connecticut river Basin. This paper depicts the improvement and use of river basin decision supportive network for forecasting flood plain benefits and financial exchange in the River Connecticut water. The choice help framework is made out of a store framework reproduction model, a natural model, and two stream powers through pressure models. The supply model recreated momentum tasks at 73 supplies and streams at areas of study for the watershed. Directed streams from select repository model unregulated streams, both measurably and spatially, for a suite of natural stream measurements identified with floodplain vegetation networks. The choice Dss supportive network was utilized to check administration situations to survey floodplain advantages, related exchange in hydroelectric power potential and flood hazard. Procedure depicted the value of huge scope repository the board choice Dss networks that fuse natural contemplations in helping with watershed arranging and ecological stream execution.

The paper centres River of Connecticut mainstream and a significant branch, the River of Farmington, to differentiate biological modification and openings for storage reoperation on streams of various quantities . The generally speaking motivation behind the paper is to exhibit how a storage model and different instruments will measure hydrologic change and change in natural stream.

DSS for Environmental and Water Resources in the Connecticut water shed (12) The study area details : Connecticut River streams at the New Hampshire (Canada) fringe south and length of $660-\mathrm{km}$ and numerous branched streams join the Connecticut River mainstream, flowing large area of Vermont other regions of Connecticut. Rain fall happens all year above $900 \mathrm{~mm}$ bellow 1,200 $\mathrm{mm}$ in the region. Pinnacle streams as generally flows in late-winter from snowmelt, and steady low streams happen in months of August to September. Method applied in this papar is, The executives options were surveyed with a connected choice decision supportive network equipped for deciphering hydrology changes and repository tasks relate to hydrologic changes, hydro electric power, storage water pool levels, 
and natural reactions. Hydrology studies has carried out and water supply hydro power generation and flood contro modelling are discussed . the river hydraulic model HEC-RAS used for the analyzing the river surface flows and elevations and flood inundations for a given periods. Arc map used to Calculate the plant habitant areas used in hydropriods. Financial measurements right now characterized as changes in hydro electric power and its frequency, flood security on the Connecticut Stream mainstream. Hydro electric power for the 11 dams on Connecticut has studied in the paper.

This paper depicted the improvement and model application of a connected choice decision supportive network to research natural openings and financial exchange offs along the Connecticut Waterway mainstream and one of its tributaries, the Farmington River. The techniques and programming that included the choice help framework distinguished potential supply reoperations that would produce floodplain benefits

The store reproduction model, final summery of the paper Environment measurements and programming advancements portrayed right now paper outline a way to deal with breaking down directed watersheds that described ecological contemplations and measures water quantities to aid watershed arranging and natural stream execution(network).

\section{S.Kaden, A.Backer et. al(1989)}

DSS Dynamic procedures in water management, The executives are described by a run of the( mill) various leveled structure and a high level of multifaceted nature. Unpredictability and the pertinence of these issues for water executives .For the national economy make the use of productive strategies and models-as decisionsupportive networks for reasonable and successful implementation of water management . Every one of these segments were thought about in the advancement of the PC helped arrangement of water the executives in the Spree stream basin, German Equitable Republic (GDR). A short depiction of the whole framework is trailed by a point by point introduction of two significant framework segments. The Dss supportive network investigation of water issues and methodologies in the zones of open-cast lignite mining, and the DSS network REHSPROX/SPROXEC for the activity used for the wastewater treatment plants. At long last, the paper manages reasonable encounters in associating exploration and practice in the improvement and usage of the framework

All these components were considered within the development of the laptop-aided device of water control in the Spree river basin, German Democratic Republic (GDR). A quick description of the complete system is observed by way of a more specified presentation of two important machine additives. The choice-assist gadget MINE serving for the evaluation of water control strategies in the regions of open-solid lignite mining, and the decision-assist machine REHSPROX/SPROXEC for the operation and improvement of wastewater remedy plants. Finally, the paper offers with practical reports in connecting research and practice within the improvement and implementation of the machine. Practice (Proceeding 1989 in IAHS Pub no.. One hundred eighty,) The development of water deliver in the Berlin place, led to a fundamental shape. This structure proved to be suitable and may be characterized via the following predominant components: (a) measuring and facts systems (records acquisition, transmission and garage), inclusive of the measuring and transmission device; (b) software program gadget (consumer software program); and (c) agency

The system development using computer for Spree river basin of water supply in the Berlin region main components 1, calibration and infromaion of the system includes data collection and, storage etc. 2 software to run by users 3. Legal and economical((organization). This Paper involve the three decision levels and scope one is planning the works, managing the works for the given period and operational and future fore casting management .It has focused on the quality and quantity of the water management. Decision-support systems developed Decision criteria for organic load self purification and BOD5 presence. Dss depends on system REH programmed and SPROUX model (developed by I.W.M (institute of watermanagement). EHSPROX/SPROXEC are the models cover portion of decision filed but the MINE DSS has covered all the possible approaches of the technical limits and its usage depends on the usage of the user.

Selected the soil, crops, live stock production etc . Modeling system analyzed the model simulation which covers the soil-crop-model consists of various mathematical related modules. GFARM was considered water erosion predicate Project for the for the crop growth model

\section{Integrated plain agriculture james C. Ascough-II , Marvin j.shaffer, et.al 1999 ;}

In this paper, Dss deals with the grate plain like Kanas, Texas etc . paper addresses the challenge to meet the extra nutrients provider to soils to incérasse production of crop without effect to the environnement . G.P.FARM (14) Dss was developed addressing all the issues concern to nutrients, water and pesticide .In This system over view described and discussed about the data input, storage database and data modules there is GUI(14) can crop growth model. Model equate is used to calculates heat. This unit help in crop growth development. Sediment erosion is calculates by using the continuity of mass équation Forester et al 1980 used in this paper to agriculture management. Water balance module and chemical transport module used to know the information related to water and chemical in given soil profiles. Paper présents the GUI base input and output result interprète in the Visual screens. Sustainable agriculture développement Can done by technology by combinions the crop and Livey stock production and contrains the 
module related to risk analysis and Aso revels the production data, yield and economic data.

\section{Conclusions}

Above fourteen paper various discussion have done on DSS on water management. The soft ware used and different types of studies carried out by the above various authors. Various methods are exploring the effective water management carried out using this review paper. Most of the review papers implies about strong and effective decision making model components are used and described with more calibration. Scope future work can be usage of integrated and advancement of the user interface, Artificial intelligence and Machine language scope of Dss are focused to obtain the water management in all aspects. Water management is require for the Hydropower, drinking and industrial usage , irrigation and other needs with compatible and economical functionality. Hydropower generation is one of the Key point in the Multipurpose reservoirs. Conflictions raised by above said purposes should avoided among the different groups of communicates for suppliant of their needs. Hence DSS in water management hydro energy distribution will also plays very important role.

\section{References}

1. K.A. Salewicz, M. Nakayama et al (Development of Web-Based DSS Development of a web-based decision support system For managing large international rivers) Global Environmental Change Volume 14, Supplement, 2004, Pages 25-37

2. Jaroslav Mysiaka , Carlo Giupponib,c , et.al, 2003 "Towards the development of a decision support system for water resource management" , From science direct, Environmental Modelling \& Software 20 (2005) 203- 214

3. Veerakcuddy Rajasekaram1 K. D. W. Nandalal2, et. al: "Decision Support System for Reservoir Water Management Conflict resolution”. 2005 J. Water Resour. Plann. Manage, 2005, 131(6): 410$419 \mathrm{ASCE} / \mathrm{nov} / \mathrm{dec}$.

4. Carlo Giupponi and and Yaella Depietri et.al (2002-2006) 2007 : “ Nostrum-Dss Guidelines for the development of Decision support System in Integrated Water Resources Management in the Mediterranean Area. “ INCO-CT-2004-509158 Nostrum-dss Network on governance, science and technology For sustainable water resource management in the Mediterranean. The role of dss tools.

5. Samsudiri Ahmad1,Mazlan Hashim1, et.al, Mohammad Idris Ali2,et.al "Décision Support System for Water Pipeline Leakage Based on Integrated GIS, Remote Sensing and Hydraulic Model" Conférence: 28th Asian Conférence on Remote Sensing 2007, ACRS 2007, Volume: 2
6. F.,A. Palma1, González2 et. al : "Managed Aquifer Recharge As a Key Elément in Sonora River Basin Management, Mexico", J. Hydrol. Eng., 2015, 20(3): B4014004,ASCE

7. Jin-Yong Choi, Bernard A. Engel,. et.al : 2005 : "Web-based GIS and spatial decision support system for water shed management", journal of hydrology, Journal of Hydro informatiques (2005) 7 (3): 165-174.

8. Veronica Ruiz-Ortiz, et.al : "Contribution of Decision support Systems to water management improvement in basins with High evaporation in Méditerranéens climates", Hydrology Research (2019) 50 (4): 1020-1036, research article 20may2019-247. https://doi.org/10.1016/j.conbuildmat.2004.05.017.

9. Baria Satyagraha, Lily Montarcih Limantara et.al 2018 : "Model of water economic value optimization based on the land use change", journal of water and land development ,2018, No. 36 (IIII): 143-152, PL ISSN 1429-7426

10. Carlo Giupponi1 and Alessandra Sgobbi 2 et.al : Water 2013, 5, 798- 18; “Decision Support Systems for Water Ressources Management in Developing Countries": Learning from Expériences in Africa" Journals : Water, Volume 5 Issue 2, 19 June 2013

11. N. Arumugam1 and S. Mohan2, et.al : "Integrated decision support system for tank irrigation system opération." J. Water Resource. Plan. Manage., 1997,123(5) :266-273

12. Suresh Kumar T, Sankar V, 2011 IEEE India Conference, INDICON, 2011, pp. 1-6, doi: 10.1109/INDCON.2011.6139523.

13. Andawayanti u., rispiningtati, antariza i.g.n. 2012. Optimum fresh water price at TITAB reservoir, Bali Province of Indonesia. Journal of Basic and Appli éd Scientifique Research. Vol. 2(7) p p. 6542-6550.1

14. james C. Ascough-II, Marvin j.shaffer, et al 1999 .GPFARM : An Integrated Decision support system for sustainable gréât plains agriculture Peer reviewd scientific content pages 951-960 in D.E stott, ,R.H.Mohtar and G.C Steinhardt (eds). 2001, sustainable Global farm. selected papers from 10 th international and soil conservation organization meeting held 1999 at purdue university and the USDA-ARA national soil érosion research laboratory

15. S. Kaden, A. Becker and A. Gnauck et. al :1989 "Decision-support systems for water management" the B altimore Symposium, May 1989, IAHS Publ no. 180,1989

16. Holling, C.S.; Gunderson, L.H.; Peterson, G.D. Sustainability and Panarchies. In Panarchy: Understanding Transformations in Human and Ecological Systems; Gunderson, L.H., Holling, C.S., Eds.; Island Press: ashington, DC, USA; London, UK, 2002; pp. 63-102 
17. John T. Hickey2 David W. Julian1; et. al 2015(A.s.c.e) Décision Support System for Water and Environnemental Ressourcés in the Connecticut River Basin 